\title{
Size judgment: The presence of a standard increases the exponent of the power law*
}

\author{
NEIL A. MACMILLAN $†$, CHARLES F. MOSCHETTO, FRANKLIN M. BIALOSTOZKY, \\ and LENORE ENGEL \\ Brooklyn College of the City University of New York, Brooklyn, New York 11210
}

\begin{abstract}
Ss judged the size of circles by the methods of magnitude estimation and magnitude production, with or without a standard figure present. The presence of the standard raised the exponent of the power law. The effect was largely independent of the position of the standard in the range of stimuli. It is argued that the standard's effect was not mediated by a difference in apparent size between perceived and remembered standards, a change in Ss' response strategies, a decrease in sequential dependencies, or other previously identified bias effects.
\end{abstract}

The scaling procedures popularized by S. S. Stevens yield power-function relationships between perceptual judgments and stimulus magnitude for a wide variety of stimulus modalities. The fact that different exponents are obtained for different modalities has been attributed by Stevens (1961) to differences in sensory transduction, and by $R$. Teghtsoonian (1971) to variation in the stimulus range available to the $E$, in combination with a constant range of numbers available to the $S$.

Unfortunately for the usefulness of such views, the exponent also depends on certain procedural variables. For example, the exponent obtained by magnitude estimation is generally found to be smaller than that obtained by magnitude production (Stevens \& Greenbaum, 1966). Stevens's view of this "regression effect" seems to have been that the "true" psychophysical function has an exponent lying somewhere between the two observed exponents, and is contaminated by the Ss' tendency not to use extreme values of the stimulus dimension under his control (see, for example, Stevens, 1971).

The present paper concerns a different procedural effect on the exponent. Both the available literature and our own experiments show that the exponent for size judgments is substantially greater when a standard stimulus is present than when it is absent. Although the "true" psychophysical function may lie between the observed ones, a full understanding of the

\footnotetext{
*Support for this investigation was provided by the City University of New York Faculty Research Award Program. We are grateful to Elizabeth Fehrer, Norma Graham, Lester Krueger, and Deborah Macmillan for valuable discussions and comments on an earlier draft. A paper based on this research was presented at the Eastern Psychological Association meetings, Philadelphia, April 1974.

tRequests for reprints should be sent to Neil A. Maemillan, Department of Psychology, Brooklyn College of CUNY, Brooklyn, New York 11210.
}

effect will not necessarily require that either function be considered invalid.

Baird (1970, p. 56) conjectured, on the basis of the literature then available, that the exponent for area might be "high" (0.9-1.2) when a standard was present and "low" (0.6-0.9) when the standard was absent. Tables 1 and 2 update the relevant aspects of his Table 3.3. ${ }^{1}$ Table 1 summarizes the results of experiments yielding high exponents; they fall into two classes: those in which a standard was present and those in which Ss were instructed to judge "area" rather than "size." Both Baird (1965, Experiment I) and M. Teghtsoonian (1965) report that Ss respond to area instructions by estimating a linear dimension and squaring. Since the exponent for length is approximately unity, a high area exponent results.

Table 2, which lists studies yielding low exponents, contains three exceptions to the generalization that the presence of a standard always yields high exponents. All three studies were performed at the Psychological Laboratories at the University of Stockholm, the source of all of the high-exponent experiments in Table 1 except those using "area" instructions. An aspect of these three studies which might account for the low exponents is that the stimulus ranges used were generally larger than for other studies from that laboratory. Increases in stimulus range are associated with decreases in the exponent, even within one modality, as has been pointed out by Poulton (1968) and R. Teghtsoonian (1973), among others, and demonstrated for area by Björkman and Strangert (1960).

The experiments presented in this paper were designed to provide a direct test of the postulated effect of a standard on the size exponent, by keeping stimulus range and other variables constant. The procedures used were magnitude estimation and magnitude production of circular area. 
Table 1

Studies Yielding High Exponents for Size Judgments

\begin{tabular}{|c|c|c|c|c|c|}
\hline Category & Experimenter & Task* & Stimuli & $\begin{array}{l}\text { timulus Range(s) } \\
\text { Maximum Area/ } \\
\text { Minimum Area }\end{array}$ & $\begin{array}{l}\text { Expo- } \\
\text { nent(s) }\end{array}$ \\
\hline \multirow{5}{*}{ Standard Present $\dagger$} & Bjorkman \& Strangert, 1960 & Ratio Estimation & Circles & $7.0-26.6$ & $.96-1.20$ \\
\hline & Ekman, 1958 & Ratio Estimation & Circles & 9.0 & .86 \\
\hline & Ekman \& Junge, 1961 & Ratio Estimation & Squares & $2.1-9.5$ & $.92-1.06$ \\
\hline & Ekman \& Junge, 1961 & $\begin{array}{l}\text { Magnitude Estimation } \\
\text { With Standard }\end{array}$ & Circles & $2.1-9.5$ & $.98-1.05$ \\
\hline & Sjoberg, 1971 & Ratio Estimation & \multirow{3}{*}{$\begin{array}{l}\text { Circles } \\
\text { Squares in } \\
\text { Larger Pattern } \\
\text { Circles }\end{array}$} & 3.9 & .96 \\
\hline \multirow{2}{*}{$\begin{array}{l}\text { Standard Absent, } \\
\text { Area Instructions }\end{array}$} & Baird, Experiment I, 1965 & Magnitude Estimation & & 24.9 & $.99+\dagger$ \\
\hline & M. Teghtsoonian, Experiment I, 1965 & Magnitude Estimation & & 81.0 & 1.03 \\
\hline
\end{tabular}

* Magnitude estimation tasks are without a standard present unless otherwise noted.

tAll studies in this category were performed at the Psychological Laboratories, University of Stockholm.

t†Estimated from published data.

\section{EXPERIMENT I}

In the first experiment, Ss performed in a magnitude estimation and a magnitude production task. It was expected, on the basis of the studies surveyed above, that Ss making judgments in the absence of a standard would produce exponents in the neighborhood of 0.75 , while those for whom a standard was present would exhibit exponents near unity.

\section{Method}

Subjects. In this and the following experiment, psychophysically naive Brooklyn College undergraduate volunteers were paid to serve as Ss. The $32 \mathrm{Ss}$ in Experiment $\mathrm{I}$ ranged in age from 18 to 35 years, with a median of 20 . Fifteen of them were male. The data of 8 other Ss were discarded for failure to follow instructions. ${ }^{2}$

Materials. For the production task, a loose-leaf book of circles was prepared. The stimuli were drawn in pencil in the centers of the $35.6 \times 43.2 \mathrm{~cm}$ pages, and every other page was left blank to insure that Ss could view only one stimulus at a time. The stimuli increased in size monotonically from the front of the book to the back, in approximately equal logarithmic units. They ranged in area from $0.20 \mathrm{~cm}^{2}$ to $615 \mathrm{~cm}^{2}$, about $3.5 \mathrm{log}$ units. For the estimation task, the stimuli consisted of 12 circles which ranged in area from $0.87 \mathrm{~cm}^{2}$ to $156 \mathrm{~cm}^{2}$ in approximately equal logarithmic steps; the size of the step was about $0.2 \log$ units, or twice that used in the production. These circles were drawn on separate sheets of white paper; the paper was the same size as that in the production book. Ss viewed the stimuli, which lay on a dark table, while sitting on a stool; the viewing distance was approximately $70 \mathrm{~cm}$. When a standard stimulus was presented at the same time as one of the other stimuli, the centers of the two stimuli were separated by about $35.6 \mathrm{~cm}$. Two standards were used; they were the 6 th and $7 \mathrm{th}$ largest stimuli of the 12 used for estimation, and had areas of $9.6 \mathrm{~cm}^{2}$ (Standard 1) and $15.1 \mathrm{~cm}^{2}$ (Standard 2).

Design. Each $S$ made 21 judgments: 11 magnitude estimations and 10 magnitude productions. There were four groups of eight $\mathrm{Ss}$ : two were "standard-present" groups, for which a standard stimulus was present during the experiment, and two were "standardabsent" groups, for which it was not. One of the "standard-present" groups and one of the "standard-absent" groups was given "conventional" instructions; the other groups

Table 2

Studies Yielding Low Exponents for Size Judgments

\begin{tabular}{|c|c|c|c|c|c|}
\hline Category & Experimenter & Task* & Stimuli & $\begin{array}{l}\text { Stimulus Range(s) } \\
\text { Maximum Area/ } \\
\text { Minimum Area }\end{array}$ & $\begin{array}{l}\text { Expo- } \\
\text { nent(s) }\end{array}$ \\
\hline $\begin{array}{l}\text { Standard Absent } \\
\text { (Baird Laboratory) }\end{array}$ & $\begin{array}{l}\text { Baird, Experiment II, } 1965 \\
\text { Baird, Romer, \& Mathias, } 1969 \\
\text { Baird, Romer, \& Mathias, } 1969 \\
\text { Baird, Romer, \& Stein, } 1970\end{array}$ & $\begin{array}{l}\text { Magnitude Estimation } \\
\text { Magnitude Estimation } \\
\text { Magnitude Estimation } \\
\text { Magnitude Estimation }\end{array}$ & $\begin{array}{l}\text { Irregular } \\
\text { Squares } \\
\text { Irregular } \\
\text { Irregular }\end{array}$ & $\begin{array}{c}144 \\
10.8,16.2 \\
10.8-19.7 \\
39\end{array}$ & $\begin{array}{l}.4-.5 \dagger \\
.81, .69 \\
.58-.70 \\
.63\end{array}$ \\
\hline $\begin{array}{l}\text { Standard Absent } \\
\text { (Teghtsoonian } \\
\text { Laboratory) }\end{array}$ & $\begin{array}{l}\text { M. Teghtsoonian, } 1965 \\
\text { M. Teghtsoonian, } 1965 \\
\text { M. \& R. Teghtsoonian, } 1971 \\
\text { M. \& R. Teghtsoonian, } 1971 \\
\text { R. \& M. Teghtsoonian, } 1970 \\
\text { Vogel \& M. Teghtsoonian, } 1972\end{array}$ & $\begin{array}{l}\text { Magnitude Estimation } \\
\text { Magnitude Estimation } \\
\text { Magnitude Estimation } \\
\text { Magnitude Estimation } \\
\text { Magnitude Estimation } \\
\text { Magnitude Estimation }\end{array}$ & $\begin{array}{l}\text { Circles } \\
\text { Irregular } \\
\text { Irregular } \\
\text { Circles } \\
\text { Irregular } \\
\text { Circles }\end{array}$ & $\begin{array}{c}81 \\
100 \\
240 \\
1000 \\
75 \\
4.7\end{array}$ & $\begin{array}{l}.76 \\
.80, .83 \\
.77 \\
.69 \\
.82, .77 \\
.81\end{array}$ \\
\hline $\begin{array}{l}\text { Standard Absent } \\
\text { (Others) }\end{array}$ & $\begin{array}{l}\text { Goldner et al, } 1971 \\
\text { Stevens \& Guirao, } 1963\end{array}$ & $\begin{array}{l}\text { Magnitude Estimation } \\
\text { Magnitude Production }\end{array}$ & $\begin{array}{l}\text { Squares } \\
\text { Squares }\end{array}$ & $\begin{array}{c}81 \\
165\end{array}$ & $\begin{array}{l}.69, .71 \\
.67, .72\end{array}$ \\
\hline $\begin{array}{l}\text { Standard Present } \\
\text { (Stockholm } \\
\text { Laboratory) }\end{array}$ & $\begin{array}{l}\text { Bjorkman \& Strangert, } 1960 \\
\text { Ekman, Lindman, \& } \\
\text { William-Olsson, 1961 } \\
\text { Mashhour \& Hosman, } 1968\end{array}$ & $\begin{array}{l}\text { Ratio Estimation } \\
\text { Magnitude Estimation } \\
\text { With Standard } \\
\text { Magnitude Estimation } \\
\text { With Standard }\end{array}$ & $\begin{array}{l}\text { Circles } \\
\text { Squares and } \\
\text { Circles } \\
\text { Circles }\end{array}$ & $\begin{array}{c}49 \\
230 \\
121\end{array}$ & $\begin{array}{c}.78 \\
.8 \\
.70-.76\end{array}$ \\
\hline
\end{tabular}


were given "fitting" instructions. These instructions are described below.

Within each group, half the Ss made estimations followed by productions, half, productions followed by estimations. Each $S$ used Standard 1 for one task and Standard 2 for the other task; furthermore, the numbers assigned to these standards were " 10 " in one condition and " 100 " in the other. Both these variables were counterbalanced across groups. The purpose of changing the standard and the modulus was to prevent Ss' performance in their second task from being directly based on remembered stimuli and responses from their first task.

Estimation Procedure. Ss were first shown one of the standards (which was shortly thereafter removed for the standard-absent group), and told to assign it the number " 10 " (or "100"). The other 11 stimuli in the estimation series were then presented in an order which was different for each $S$, and random except that the first stimulus could not be one of the two smallest or two largest in the series.

Production Procedure. ${ }^{3}$ Again, a standard was presented and assigned a modulus. Ss for whom the modulus was " 10 " were then asked to select figures corresponding to the numbers $2,3,4,6,8$, $12,17,25,35$, and 50 ; those for whom the modulus was " 100 " were given numbers 10 times as large. The order in which the numbers were given was different for each $S$, and random except that the first stimulus could not be one of the two smallest or two largest in the set. Ss were instructed to bracket their responses by either starting with the smallest stimulus, leafing through the book until they were sure they had gone too far and then returning to their best estimate, or the opposite. Some stimuli were judged starting at the end of the book containing the smallest circle ("up" judgments), some from the end containing the largest ("down" judgments). Whether a judgment was "up" or "down" was subject to the following constraints: (1) Within each group, half the Ss judged each stimulus "up," half "down"; (2) for each S, either three of the stimuli smaller than the standard and two larger than the standard were judged "up" and the remainder "down," or vice versa; (3) when the stimuli are considered in increasing order of magnitude, no more than two consecutive stimuli were judged in the same direction; and (4) when the stimuli are considered in the order they were presented, no more than two consecutive stimuli were judged in the same direction. Constraint 4 was violated for one S.

In both estimation and production, the $S$ made his response orally at his own rate; the E recorded it (out of sight of the $S$ ) before presenting the next stimulus. The time spent observing each figure was recorded by the $E$ without the $S$ 's knowledge.

Instructions. Ss in the standard-present, conventional. instruction group received the following instructions:

"I am going to show you a series of circles. Your task is to tell how large these circles look by assigning numbers to them.

"This circle [present standard] will be present throughout the experiment; call its size ' 100 ' [or ' 10 '] . As I show you other circles, I want you to assign numbers to them proportional to how large they appear. For example, if a circle appears twice as large as the standard, call it ' 200 '; if it appears one-fourth as large, call it '25,' and so forth. Try not to worry about being consistent; just give me a number which represents how large the circle appears to you. Do you have any questions?"

Ss in the standard-absent, conventional-instruction group received similar instructions, but were told that the standard would not remain throughout the experiment. These are fairly typical instructions for size (as opposed to area) judgment.

Pilot work had shown that some of our Ss were likely to interpret these instructions as a request to judge the linear extent of the figures. The "fitting"-instruction groups were included to insure that some Ss, at least, would not do this. The instructions they were given corresponded to the reported strategies of virtually all our pilot Ss except those reporting linear judgments. After the standard was presented, they were told: "The way in which I would like you to determine the size of these circles is to try to picture how many times the smaller of the two circles will fit into the larger, and then give me a number reflecting that relationship. For example, if the circle $I$ present is larger than the standard, and the standard seems to fit into this circle exactly two times, call the circle '200.' If the circle I present is smaller than the standard, and seems to fit into it exactly four times, call the circle ' $25,{ }^{\prime}, 4$

\section{Results}

The exponents of the individual Ss were estimated by the slopes of the best-fitting straight lines relating the logarithms of these numbers to log stimulus area; the mean exponents for the various conditions are shown in Table 3 . The correlation between log stimulus and $\log$ response for an individual $S$ in a particular condition averaged 0.979 ; for the grouped data (e.g., for estimation, standard-present, conventional instructions), all eight correlations exceeded 0.99. Although high, these correlations could conceal systematic deviations from powerfunction fit, but inspection of the individual functions failed to reveal any.

An analysis of variance (Standard by Instructions by Task) revealed an effect of the presence of the standard $[\mathrm{F}(1,28)=5.60, \mathrm{p}<.05]$ and a marginal effect of instructions $[\mathrm{F}(1,28)=3.54, .05<\mathrm{p}<.10]$. Ss receiving conventional instructions were classified into two groups on the basis of postexperimental interviews: those who adopted "fitting" strategies and those who reported judging a linear dimension. ${ }^{5}$ If the former $S$ s are grouped with those who were given "fitting" instructions, an analysis of variance can be performed on what is now a Standard by Strategy by Task design. The effect of strategy is strong $[F(1,28)$ $=14.9, \mathrm{p}<.01]$, and there is a marginal interaction between strategy and standard $[\mathrm{F}(1,28)=3.33$, $.05<\mathrm{p}<.10]$. The interaction reflects the fact that the presence of the standard matters only to Ss who are "fitting," not to those who are judging linear extent.

If $\mathrm{Ss}$ who adopted linear strategies are ignored, Experiment I permits two clear conclusions: (1) The presence of a standard increases the power law exponent, and (2) the regression effect generally found when estimation and production are compared does not occur here. Linear $S$ s produced essentially linear results (i.e., exponents near 0.5 ) in all conditions.

Table 3

Mean Exponents of Individual Best-Fitting Power Functions: Experiment I

\begin{tabular}{|c|c|c|c|c|c|}
\hline & \multirow[b]{2}{*}{$\mathbf{N}$} & \multicolumn{2}{|c|}{$\begin{array}{c}\text { Conventional } \\
\text { Instructions }\end{array}$} & \multicolumn{2}{|c|}{$\begin{array}{c}\text { Fitting } \\
\text { Instructions }\end{array}$} \\
\hline & & $\mathrm{E}$ & $\mathrm{P}$ & E & $\mathbf{P}$ \\
\hline $\begin{array}{c}\text { Standard Present } \\
\text { Linear Strategy } \\
\text { Fitting Strategy }\end{array}$ & $\begin{array}{l}8 \\
4 \\
4\end{array}$ & $\begin{array}{l}.73 \\
.58 \\
.88\end{array}$ & $\begin{array}{l}.62 \\
.55 \\
.69\end{array}$ & .82 & .81 \\
\hline $\begin{array}{c}\text { Standard Absent } \\
\text { Linear Strategy } \\
\text { Fitting Strategy }\end{array}$ & $\begin{array}{l}8 \\
6 \\
2\end{array}$ & $\begin{array}{l}.63 \\
.59 \\
.76\end{array}$ & $\begin{array}{l}.62 \\
.58 \\
.73\end{array}$ & .65 & .66 \\
\hline
\end{tabular}

Note $-E=$ estimation, $P=$ production 
The time data were not illuminating. Time to make an estimation averaged $13.7 \mathrm{sec}$ with a standard, $11.0 \mathrm{sec}$ without; productions averaged $41.1 \mathrm{sec}$ with a standard, 37.1 sec without. It is our impression that the extra few seconds used by the $S s$ in the standard-present groups were devoted to looking back and forth between the two stimuli. Time did not vary in any systematic way with the area of the figure being judged. The correlations, across Ss, of average judgment time and exponent were insignificantly negative for each of the four main conditions. This statistical pattern does not suggest to us an account of the experimental results in terms of judgment time.

\section{Discussion}

The proportion of Ss who interpret "size" to mean "linear extent," in the absence of instructions to the contrary, is quite high, and it would appear that S populations differ on this parameter. Previous studies which have reported distributions of exponents for individual Ss have found fewer "linear" Ss: about $24 \%$ of M. Teghtsoonian's (1965) Ss (as compared with $44 \%$ of ours) had exponents less than 0.65 . Although the fact that certain Ss interpret "size" in this fashion may have interesting implications, their data certainly differ systematically from those of other Ss. In particular, it does not appear that judgment of linear extent is much affected by the presence of the standard, even though that variable has a substantial effect on size judgments by nonlinear Ss.

One interpretation of the effect of the standard on the exponent is that the presence of the standard serves to counteract the $S$ 's tendency to avoid extreme judgments. This explanation makes a prediction about magnitude production, as follows: the presumed conservative response bias in production is a tendency to reduce the range of circles selected by the $S$. If the presence of the standard counteracts this bias, it should yield a lower, rather than a higher, exponent than standard absence. This is not what is observed. Rather, the presence of the standard increases the exponent in production as well as in estimation. We thus reject this explanation of the data.

The production task differs from conventional production tasks in several ways which may have influenced the results. In particular, $S s^{\prime}$ responses may sometimes have been mediated by the number of pages a particular circle was from the beginning or end of the book. Although it is not obvious how this might have led to the results, a production task more like conventional ones is desirable.

All the obtained exponents are smaller than predicted. The simplest explanation for this is that the range of stimuli used in Experiment I was larger than that of any study listed in Table $\mathbf{I}$.

\section{EXPERIMENT II}

The results of Experiment I might be accounted for in terms of another, well-documented procedural effect, that of the stimulus range on the exponent. Suppose that the presence of the standard serves to effectively divide the stimulus range into two subranges, stimuli larger and smaller than the standard. Then an $S$ judging stimuli in the presence of a standard would be influenced by a smaller range of stimuli, and should have a higher exponent, than an $\mathrm{S}$ making judgments in the absence of a standard.

This explanation was tested in Experiment II by using standards which were at one end of the range of stimuli. If the presence of such standards were to have no effect on the exponent, the explanation would be supported; if it still increased the exponent, some other explanation would be needed.

\section{Method}

Subjects. The 48 Ss in Experiment II ranged in age from 16 to 21 years, with a median of 18 . Twenty-eight of them were male. The data of 9 other $S$ s were discarded for failure to follow instructions.

Materials. Stimuli were projected on a $1.1 \times 1.4 \mathrm{~m}$ screen, $3 \mathrm{~m}$ from the $S$. The circles appeared as light patches on the screen, the contrast ratio between the circles and the background being about 2.5 . For the production task, an iris was placed in the beam of a projector, and was adjusted by the $E$ in response to the $S$ 's instructions. The iris produced slightly decagonal "circles." The 11 stimuli used in estimation ranged in area from $9.6 \mathrm{~cm}^{2}$ to $815.7 \mathrm{~cm}^{2}$, about $1.9 \log$ units, and were approximately equally logarithmically spaced. In the production task, figures ranging in area from $3.3 \mathrm{~cm}^{2}$ to $1.4 \mathrm{~m}^{2}$ were available. When a standard was present, it appeared above and $32 \mathrm{deg}$ to one side of the variable stimulus, and the distance between the centers of the two figures was $57 \mathrm{~cm}$. The $1 \mathrm{st}, 6$ th, and 11 th of the 11 estimation stimuli were used as standards.

Design. Each $S$ made 20 judgments: 10 magnitude estimations and 10 magnitude productions. There were six groups of eight $\mathrm{Ss}$, three standard-present and three standard-absent groups; the three subgroups of each type differed in the size of the standard with which they were presented. Within each group, half the Ss made estimations followed by productions, half, productions followed by estimations. Ss using a small standard were given a modulus of either " 1 " or " 10 ," those using a medium standard either " 10 " or " 100 ," and those using a large standard either " 100 " or " $1,000 "$ "; whichever modulus was not used for estimation was used for production.

Procedures. The $S$ proceeded essentially as in Experiment $I$ in the estimation task. In the production task, the $S$ was told to instruct the $E$ on how to change the size of the figure until it matched the number that had been presented. The figure was always set to its maximum or minimum size at the start of a trial, the sequence being under the same constraints as in Experiment $I$. Ss in the small-standard " 1 "-modulus group were given numbers ranging from 1.5 to 25 ; those in the medium-standard "10"-modulus group, numbers from 2 to 50 ; those in the large-standard "100"-modulus group, numbers from 4 to 75 ; and those in the other (larger modulus) groups, numbers 10 times as large as those for the corresponding small-modulus group. In all cases, the numbers were approximately logarithmically spaced.

In both estimation and production, each $S$ was presented with stimuli in a different order, random except that the first stimulus could not be one of the two smallest or largest. "Fitting" instructions similar to those in Experiment I were used for all Ss. 


\section{Results and Discussion}

Mean individual exponents are given in Table 4. The correlation between log stimulus and log response for an individual $\mathrm{S}$ and condition averaged 0.972; all correlations based on grouped data exceeded 0.99 .

The effect of the presence of the standard is strong $[\mathrm{F}(1,42)=25.1, \mathrm{p}<.001]$. The hypothesis that this effect would not hold for standards at an extreme of the stimulus range was evaluated by performing an analysis of variance on the small- and large-standard groups only; there was still an effect of presence of the standard $[\mathrm{F}(1,28)=8.14, \mathrm{p}<.01]$. The effect is largest for a standard in the middle of the range, as evidenced by a marginal interaction in the full analysis of variance between presence of standard and size of standard $[F(2,42)=3.23, .05<p<.10]$, but it is still substantial for small or large standards.

As in Experiment I, there was no regression effect; in fact, the difference between estimation and production exponents was significantly in the opposite direction $[F(1,42)=8.5, \mathrm{p}<.01]$.

The size of the standard had no effect $[F(2,42)=$ 0.24 ]. This is contrary to a generalization of Poulton's (1968) that the exponent is higher when the standard is in the middle of the stimulus range than when it is at one extreme. Poulton's generalization is based primarily on several loudness experiments (Stevens, 1956; Hellman \& Zwislocki, 1961; Beck \& Shaw, $1965)$ in which an estimation procedure was used and the standard was presented, or at least available, on every trial. These experiments are most similar to our standard-present, estimation conditions, and in those conditions the exponent varied in exactly the way Poulton predicts. The effect of standard magnitude on the exponent may be the same in different modalities, but appears to interact with task and presence of the standard.

\section{GENERAL DISCUSSION}

\section{Effect of the Standard}

Two proposed explanations for the effect of the presence of the standard have already been rejected: that the standard serves to counteract a conservative response bias, and that it serves to divide the effective stimulus range. We now consider several other possibilities.

Whether a standard is perceptually present or must be remembered has long been known to affect judgment: the traces of remembered standards are said to "fade," so that judgments re remembered standards are greater than judgments re perceived ones. A straightforward interpretation of this idea leads to no predicted effect of standard on the exponent, just a decrease in the scale factor. However, the fading trace hypothesis can be combined with the effect of position of standard in the stimulus range described in the discussion following Experiment II above. If a remembered standard in the middle of the stimulus range fades, it becomes equivalent to a perceived standard near the bottom of the range, and should yield a lower exponent than a perceived standard in midrange. This model can be rejected by considering the data with a large standard: a remembered large standard should gravitate towards the middle of the stimulus range, yielding a higher exponent than a perceived large standard. This does not occur, as Table 4 shows.

It may be that Ss making judgments in the absence of a standard adopt strategies which systematically differ from those of Ss for whom a standard is present. The postexperimental questionnaires revealed three main strategies that Ss following "fitting" instructions used: (1) filling the larger circle with copies of the smaller one, starting at one edge and proceeding around the perimeter; (2) filling the larger circle with copies of the smaller one, starting in the center; and (3) placing the smaller one in the center of the larger and expanding it. The first strategy was the most popular, in all conditions. There were no systematic differences in exponent as a function of strategy. Had the entire analysis in Experiment II been performed only on Ss using Strategy 1, the average exponents would have been very nearly the same as those in Table 4.

A final plausible explanation invokes sequential effects, attempting to explain the overall effect in terms of a microeffect. Ward (1973) has shown that, when Ss are instructed to use the previous stimulus as a standard in loudness estimation, the judgment of a given stimulus is an increasing function of the magnitude of the previous stimulus. Because small stimuli tend to be preceded by large ones, and vice versa, this bias leads to a reduced estimate of the exponent. It is not unreasonable to suppose that such sequential effects would be stronger in the absence of the standard than in its presence.

Cross (1973) has suggested a technique for correcting scaling data for such sequential effects. He proposes a model which leads to the following modification of the power law:

$$
\log N_{i j}=\log a+m \log S_{i}+b \log S_{j},
$$

where $S_{i}$ is the magnitude of the stimulus being judged, $S_{j}$ is the magnitude of the previous stimulus, and $N_{i j}$ is the response. The corrected exponent $m$ and the strength of the sequential bias $b$ can be

Table 4

Mean Exponents of Individual Best-Fitting Power Functions: Experiment II

\begin{tabular}{lccccccc}
\hline & \multicolumn{3}{c}{ Estimation } & & \multicolumn{3}{c}{ Production } \\
\cline { 2 - 4 } \cline { 5 - 8 } & SS & MS & LS & & SS & MS & LS \\
\hline Standard Present & .84 & .97 & .80 & & .70 & .79 & .84 \\
Standard Absent & .75 & .70 & .71 & & .67 & .61 & .65 \\
\hline
\end{tabular}

Note-SS = small standard, $M S=$ medium, and $L S=$ large. 
estimated by multiple regression. If sequential effects underlie the differences in exponents in the present study, then estimates of $m$ should be the same whether the standard is present or absent, but estimates of $b$ should be greater when the standard is absent.

This analysis was performed on the data of Experiment II. Estimates of $b$ ranged from -0.055 to 0.044 . Estimates of $m$ differed from the exponents estimated from the grouped data in the usual way by an average of 0.005 in estimation and 0.0018 in production; the effect was slightly greater for standard-present than for standard-absent groups. Clearly, sequential effects do not account for the effect of the presence of the standard. Cross (1973) considers that sequential dependencies may underlie the regression effect. The present data, which display neither, are consistent with his explanation.

It is worth asking whether the explanation for the exponent difference is to be found in general scaling principles or in an understanding of size scaling in particular. Does the effect of the presence of the standard occur for other continua?

Magnitude estimation experiments explicitly varying the availability of the standard have been performed for heaviness and loudness. Stevens and Galanter (1957) report three studies on heaviness. When the standard was always available, an exponent of about 1.5 obtained; when the standard was available only every third trial, the exponent was about 1.4; and when there was no standard, the exponent was about 1.2. These results are somewhat analogous to our results for size, although the standard in Stevens and Galanter's study reduced rather than increased veridicality. J. C. Stevens and Tulving (1957) found an effect of standard on loudness: presenting the standard on every trial increased the exponent from 0.28 to 0.35 . On the other hand, Stevens (1956) failed to find an effect: whether the standard was available at all times, presented only once, or never presented, the exponent for loudness was 0.3 .

\section{Estimation vs Production}

Stevens and Greenbaum (1966) reported a number of auditory and visual scaling experiments in which Ss tended to reduce the range of the variable over which they had control, leading in particular to a lower estimated exponent for estimation than for production. Our experiments show, if anything, the opposite: the estimation exponent is generally equal to or greater than the production exponent.

To our knowledge, the only investigators to study magnitude production of size have been Stevens and Guirao (1963). They estimated an exponent of about 0.7 , which is towards the low end of the range of exponents in Tables 1 and 2, but they did not perform estimation experiments, so no direct comparison can be made. In both their experiment and ours, the low exponents could have resulted from the relatively small range of numerical stimuli used.

\section{SUMMARY AND CONCLUSIONS}

Size judgments of circular area are a power function of physical area, but the exponent is higher when a standard figure is present during judgment. The effect seems to occur in both magnitude estimation and production, and is independent of the position of the standard in the range of stimuli.

These results have an ironic implication for cartography, a practical science in which size scaling results have been applied. The fact that the exponent for apparent size (as measured in experiments in which a standard is not present) is substantially less than one has led to the suggestion that cartographers draw symbols for population, for example, so that (area) 0.7 , rather than area per se, is proportional to population (Stevens \& Guirao, 1963). The present data suggest that this is inappropriate, since in map reading there are many "standards" present to aid judgment, and the perceived size of such symbols is close to proportional to real size.

\section{REFERENCES}

Anderson, N. H., \& Weiss, D. J. Test of a multiplying model for estimated area of rectangles. American Journal of Psychology. 1971, 84, 543-548.

BAIRD, J. C. Area and distance estimation of single and multiple stimuli. Vision Research, 1965, 5, 661-678.

BArRd, J. C. Psychophysical analysis of visual space. New York: Pergamon Press, 1970.

Baird, J. C., Romer, D., \& Mathias, C. G. Area and randomness estimates of complex stimuli. Perceptual \& Motor Skills, 1969, 28. $659-669$.

Baird, J. C., Romer, D., \& Stein, T. Test of a cognitive theory of psychophysics: Size discrimination. Perceptual \& Motor Skills, 1970, 30, 495-501.

Beck, J., \& Shaw, W. A. Magnitude of the standard, numerical value of the standard, and stimulus spacing in the estimation of loudness. Perceptual \& Motor Skills, 1965, 21, 151-156.

BJörkman, M., \& STRANGert, B. The relationship between ratio estimates and stimulus dispersion. Reports from the Psychological Laboratory, University of Stockholm, No. 81, 1960.

Cross. D. V. Sequential dependencies and regression in psychophysical judgments. Perception \& Psychophysics, 1973, 14, 547.552 .

EkMAN, G. Two generalized ratio scaling methods. Journal of Psychology, 1958, 45, 287-295.

Ekman, G., \& Junge, K. Psychophysical relations in visual perception of length, area, and volume. Scandinavian Journal of Psychology, 1961, 2, 1-10.

Ekman, G., Lindman, R., \& William-Olsson, W. A psychophysical study of cartographic symbols. Perceptual \& Motor Skills, 1961, 13, 355-368.

Goldner, J., Reuder, M. E., Riba, B., Jarmon, D. Neutral vs ego-involving instructions: Effects on judgments of magnitude estimation. Perception \& Psychophysics, 1971, 9, 84-88.

Hellman, R. P., \& Zwislocki, J. Some factors affecting the estimation of loudness. Journal of the Acoustical Society of America. $1961,33,687-694$.

Helson, H., \& Bevan, W. An investigation of variables in judgment of relative area. Journal of Experimental Psychology, 1964, 67. $335 \cdot 341$. 
Krueger, L. E. Perceived numerosity. Perception \& Psychophysics, 1972, 11, 5-9.

Mashmour, M., \& Hosman, J. On the new "psychophysical law": A validation study. Perception \& Psychophysics, 1968, 3, 367-375.

Poulton, E. C. The new psychophysics: Six models for magnitude estimation. Psychological Bulletin, 1968, 69, 1-19.

SJöBERG, L. Three models for the analysis of subjective ratios. Scandinavian Journal of Psychology, 1971, 12, 217-240.

Stevens, J. C., \& Tulving, E. Estimations of loudness by a group of untrained observers. American Journal of Psychology, 1957, 70, 600-605.

STEVENS, S. S. The direct estimation of sensory magnitudes-loudness. A merican Journal of Psychology, 1956, 69, 1-25.

Stevens, S. S. The psychophysics of sensory function. In W. A. Rosenblith (Ed.), Sensory communication. Cambridge. Mass: M.I.T. Press, 1961.

Stevens, S. S. Issues in psychophysical measurement. Psychological Review, 1971, 78, 426-450.

Stevens, S. S., \& Galanter, E. Ratio scales and category scales for a dozen perceptual continua. Journal of Experimental Psychology. $1957,54,377.411$.

Stevens, S. S., \& Greenbaum, H. B. Regression effect in psychophysical judgment. Perception \& Psychophysics, 1966, 1, 439-446.

STEvens. S. S., \& Gutrao, M. Subjective scaling of length and area and matching of length to loudness and brightness. Journal of Experimental Psychology, 1963, 66, 177-186.

Teghtsoonian, M. The judgment of size. American Journal of Psychology, 1965, 78, 392-402.

Teghtsoonian, M., \& Teghtsoonian, R. How repeatable are Stevens's power law exponents for individual subjects? Perception \& Psychophysics, 1971, 10, 147-149.

Teghtsoonian, R. On the exponents in Stevens' law and the constant in Ekman's law. Psychological Review, 1971, 78, 71-80.

Teghtsoonian, R. Range effects in psychophysical scaling and a revision of Stevens' law. American Journal of Psychology, 1973, 86. $3-28$.

Teghtsoonian, R., \& Teghtsoonian, M. Effects of size and distance on magnitude estimations of apparent size. American Journal of Psychology, 1970, 83, 601-612.

Vogel, J. M., \& Teghtsoonian, M. The effects of perspective alterations on apparent size and distance scales. Perception \& Psychophysics, 1972, 11, 294-298.
WARD, L. M. Repeated magnitude estimations with a variable standard: Sequential effects and other properties. Perception \& Psychophysics, 1973, 13, 193-200.

\section{NOTES}

1. Studies in which the standard and comparison stimuli were displayed concentrically (e.g.. Helson \& Bevan, 1964) are not summarized in Tables 1 and 2.

2. Of the eight $S s$ dropped from Experiment I, two made inconsistent use of numbers, and six reported using a linear rather than a fitting strategy, contrary to instructions. Nine Ss were dropped from Experiment II, three for inconsistent number use and six for reporting a linear strategy. Individual exponents for Ss reporting a linear strategy averaged 0.58 in estimation and 0.57 in production, confirming these Ss' reports.

3. The "production" task in Experiment I is modelled on a similar task used by Krueger (1972) in studying numerosity.

4. The fitting instructions were ambiguous with regard to whether the $S$ was supposed to imagine the smaller circles to be tangent to each other and circumscribed by the larger circle, or overlapping so as to compensate for the portion of the large circle which would be "left over" under the former strategy. The exponent predicted by the nonoverlapping strategy can be computed for sets of circles in which the larger circle contains exactly n (nonoverlapping) copies of the smaller one; if $\mathrm{n}$ varies from 1 to 5 and stimuli both larger and smaller than the standard are considered, the predicted exponent is 0.73 . The exponent predicted by the overlapping strategy is obviously higher. When questioned in the postexperimental interview, most Ss reported using a nonoverlapping strategy, but adjusting their responses to take account of the remaining area.

5. No $S$ reported using the strategy of estimating a linear dimension and then squaring it, as did Ss of M. Teghtsoonian (1965) and Baird (1965). Anderson and Weiss (1971) have suggested a strategy they call "additive integration" which is apparently similar to the fitting strategy our Ss used.

\section{(Received for publication February 8, 1974;} revision received June 12,1974 .) 